\title{
Exploitation of Hybrid Vigor for Identification of Promising Sorghum F1 Hybrid for High Grain Yield and Resistance to Sorghum Midge
}

\author{
Massaoudou Hamidou $\mathbb{D}^{1,2}$ Oumarou Souleymane, ${ }^{1,2}$ Mahamadou Salifou, ${ }^{1,2}$ \\ Malick N. Ba, ${ }^{3}$ Issoufou Kapran, ${ }^{1}$ Vernon Gracen, ${ }^{2,4}$ Kwado Ofori, ${ }^{2}$ \\ and Eric Yirenkyi Danquah ${ }^{2}$ \\ ${ }^{1}$ Institut National de la Recherche Agronomique du Niger (INRAN), BP 429, Niamey, Niger \\ ${ }^{2}$ West Africa Centre for Crop Improvement, University of Ghana, PMB 30 Legon, Accra, Ghana \\ ${ }^{3}$ International Crop Research Institute for the Semi-Arid Tropics, BP 12404, Niamey, Niger \\ ${ }^{4}$ Department of Plant Breeding and Genetics, Cornell University, 520 Bradfield Hall, Ithaca, NY 14850, USA
}

Correspondence should be addressed to Massaoudou Hamidou; hmassaoud@yahoo.fr

Received 26 September 2020; Accepted 7 November 2020; Published 19 November 2020

Academic Editor: Isabel Marques

Copyright (C) 2020 Massaoudou Hamidou et al. This is an open access article distributed under the Creative Commons Attribution License, which permits unrestricted use, distribution, and reproduction in any medium, provided the original work is properly cited.

Sorghum is the second most grown cereal crop in Niger. However, sorghum production in the country is dominated by indigenous cultivars with low productivity. Productivity in grain sorghum has been achieved in developing countries around the world using hybrids. This study was conducted to evaluate heterosis in $\mathrm{F}_{1}$ sorghum hybrids for grain yield and resistance to midge. Fifty $\mathrm{F}_{1}$ sorghum hybrids were evaluated for grain yield and resistance to midge. Variation for grain yield, midge resistance, and flowering time was observed. The magnitude of better parent heterosis for grain yield and resistance to midge varied significantly among hybrids. Four hybrids combined high better parent heterosis for both grain yield and resistance to midge while eight hybrids were better than their better parent for resistance to midge. These hybrids performed well for grain yield and/or resistance to midge. Therefore, the parental lines involved in these hybrids can be advanced for commercial hybrids production or used in sorghum improvement programs.

\section{Introduction}

Sorghum (Sorghum bicolor (L.) Moench) is a tropical cereal crop grown in a wide range of environments where it plays an important role as a staple food for several millions of people all over the world. According to FAO [1], sorghum is the fifth most important cereal crop after wheat, maize, rice, and barley. In Niger, sorghum is the second most grown cereal after millet. However, sorghum production rarely meets the demand of the growing population in the country. Grain sorghum yields are very low, about 0.280 tons/ha, which is far below the genetic potential of the crop in countries such as USA (4.3 tons/ha), Argentina (4.9 tons/ ha), and China (3.2 tons/ha) [1]. The low production is attributed, not only to abiotic and biotic stresses, but also to the use of low yielding local varieties susceptible to the above constraints [2].

Sorghum midge, Stenodiplosis sorghicola (Coquillett 1898), is one of the most damaging pests of grain sorghum [3]. Globally, losses due to sorghum midge are known to vary over seasons and locations, but are thought to approximate $10-15 \%$ of the world sorghum crop production [4]. In Niger, according to Amadou [5], sorghum midge appears in the field around mid-September to early October when sorghum is flowering, thereby causing serious damage to sorghum yield. The author documented a yield reduction of about $30 \%$ to $40 \%$ caused by the insect in Niger. On the other hand, yield reduction of about $55.8 \%$ to $67.3 \%$ was recorded in the country by Kadi Kadi et al. [6]. These data clearly indicate that local sorghum varieties grown in Niger 
are highly susceptible to midge infestation. According to Hamidou et al. [7], sorghum midge is well known by farmers in Niger. However, early planting is the only midge control measure used by sorghum farmers. Since the timing of rainy seasons in the Sahel is unpredictable, it is difficult to determine a planting time at which sorghum midge incidence can be prevented.

Grain yield and resistance to midge in sorghum can be increased by exploiting heterosis or hybrid vigor. Heterosis breeding has been used to increase sorghum grain productivity by $47 \%$ in China and $50 \%$ in India from the 1960 s to the 1990s [8]. In Australia, midge-resistant sorghum has been used in sorghum midge control. As a result, a worldwide recognized integrated pest management (IPM) program was implemented [9].

The cost of producing hybrids is only justified when the performance of the hybrids surpasses that of their parents [10]. According to Hochholdinger and Hoecker [11], the potential of sorghum hybrids is estimated from the percentage increase or decrease of their performance over the midparent (midparent heterosis), better parent (heterobeltiosis or better parent heterosis), and the standard check (standard heterosis). However, Lamkey and Edwards [12] indicate that heterobeltiosis or better parent heterosis is more realistic and practical because it compares the hybrid with the best parent unlike midparent heterosis that compares the hybrid with the mean of the two parents. Furthermore, Reif et al. [13] suggested that the selection of superior parents for outstanding hybrids should depend on superior heterobeltiosis. To date, only one sorghum hybrid has been developed and released to farmers in Niger. However, this hybrid does not satisfy farmers in the large sorghum producing agroecological areas of the country because of late maturity and susceptibility to midge. The development of early maturing sorghum hybrids with high grain yield and resistance to midge is needed to address low sorghum productivity in Niger. This study was undertaken to estimate better parent heterosis in experimental $\mathrm{F}_{1}$ hybrids for grain yield, resistance to sorghum midge, and time to flowering.

\section{Materials and Methods}

2.1. Experimental Materials. The experimental materials consisted of fifty $\mathrm{F}_{1}$ hybrids generated using line by tester mating design and two local checks. The hybrids were obtained by crossing 25 recombinant inbred lines (RILs) onto two male-sterile midge-resistant lines. The inbred lines used as male parents were $\mathrm{F}_{1-4}$ lines developed from a cross between a local sorghum variety (MDK) and an exotic sorghum midge-resistant cultivar from ICRISAT (ICSV88032) using the single-seed descent breeding method (SSD). The male-sterile lines were TX640 from Texas A\&M University, USA, and QL33 from Queensland University, Australia.

2.2. Experimental Site. A field experiment was conducted during the 2015 rainy season at the research station of INRAN at Konni in Niger Republic. Konni has a latitude of $13^{\circ} 47^{\prime} 23^{\prime \prime}$ North and a longitude of $5^{\circ} 14^{\prime} 57^{\prime \prime}$ East, an average annual rainfall of $589.7 \mathrm{~mm}$, and an average temperature of $29.3^{\circ} \mathrm{C}$.

2.3. Experimental Design. The experimental design was an alpha (0.1) lattice with 3 replications. However, blocking was not significant and the data were reanalyzed using randomized complete block design. Each genotype was grown in a single 3 meters row in each replication. The intra- and interrow spacing was $0.20 \mathrm{~m} \times 0.80 \mathrm{~m}$. Five seeds were panted and thinned to three plants per stand three weeks after planting. Weeding was done when necessary, and standard cultural practices for optimum sorghum production were carried out. Harvesting was done at physiological maturity. In order to evaluate midge damage on the panicles, three panicles were covered at emergence using selfing bags. At harvesting, panicle and grain mass were recorded for the three covered and three noncovered panicles. The loss in grain yield in three noncovered panicles was expressed as a percentage of grain yields in covered panicles.

2.4. Data Collection and Analysis. Data collected were grain yield (GY), days to $50 \%$ flowering (FF), and midge damage (MD). Grain yield was measured in tons per hectare adjusted to grain moisture content at $12 \%$. Days to $50 \%$ flowering was recorded by counting the number of days from planting to when $50 \%$ of the plants in a plot flowered. Midge damage was calculated as loss of grain yield in three noncovered panicles expressed as a percentage of grain yield in three covered panicles. Analysis of variance was computed for grain yield, days to $50 \%$ flowering, and midge damage using the model described by Kempthorne [14] in SAS 9.3 software.

Heterosis, expressed as percentage increase or decrease in hybrid F1 over its better parent (BP) value, was calculated as described by Turner [15] and Hayes et al., [16] using the following formula:

$$
\text { better parent heterosis }(\%)=\frac{F_{1}-\mathrm{BP}}{\mathrm{BP}} \times 100,
$$

where $F_{1}=$ mean performance of $F_{1}$ and $\mathrm{BP}=$ mean performance of the better parent.

For computing better parent heterosis for grain yield, hybrids were compared with their higher yielding parent. Hybrids were compared to parents for low percentage of yield lost and fewer days to $50 \%$ flowering.

\section{Results}

3.1. Analysis of Variance. The analysis of variance showed significant differences among lines and the interaction of lines by testers for the traits under study. However, testers were significantly different for all the study traits except midge damage. The magnitude of mean squares indicates that crosses were different for grain yield, midge damage, and flowering time (Table 1). 
TABLE 1: Mean squares for traits of 50 experimental hybrids evaluated in the 2015 rainy season.

\begin{tabular}{lcccc}
\hline Source of variation & d.f. & FF & GY & MD \\
\hline Rep & 2 & $3.795^{*}$ & $42540.29^{*}$ & $1.19^{*}$ \\
Lines & 24 & $8.371^{*}$ & $21725.33^{*}$ & $0.15^{*}$ \\
Testers & 1 & $36.358^{*}$ & $214220.59^{* *}$ & $0.05^{\text {ns }}$ \\
Lines $\times$ testers & 24 & $9.34^{*}$ & $10620.12^{*}$ & $0.11^{*}$ \\
Residual & 97 & 6.679 & 11339.524 & 0.07 \\
CV & & 3.950 & 52.810 & 49.628
\end{tabular}

$\mathrm{SV}=$ seedling vigor; $\mathrm{PH}=$ plant height; $\mathrm{FF}=$ days to $50 \%$ flowering; TSW $=1000$ seed weight; $\mathrm{GY}=$ grain yield; $\mathrm{MD}=$ midge damage; $\mathrm{ns}=$ nonsignificant; ${ }^{*}$ significant at $5 \%{ }^{* *}$ significant at $1 \%$.

3.2. Performance of the Experimental Hybrids. The range of mean performance was significant for grain yield and midge damage among genotypes. However, the range of mean performance of flowering time did not vary significantly. Grain yield of the crosses ranged from $1.17 \mathrm{t} /$ ha for the hybrid QL33 $\times$ L11 to 12.70 t/ha for the hybrid TX640 $\times$ L18. The range of yield reduction caused by midge was from $15 \%$ for hybrid QL33 $\times$ L4 to $84 \%$ for hybrid TX640 $\times$ L19. The range of days to $50 \%$ flowering was from 61 DAP for hybrid TX640 $\times$ L21 to 69 DAP for hybrid TX640 $\times$ L12 (Table 2).

3.3. Better Parent Heterosis. The better parent heterosis for grain yield varied from $3.62 \%$ for QL33 $\times$ L5 to $61.40 \%$ for the hybrid TX $640 \times \mathrm{L} 24$. The negative value of better parent heterosis for the resistance to midge ranges from $-1.64 \%$ for the hybrid QL33 $\times$ L15 to $-74.14 \%$ for the hybrid QL33 $\times$ L4 . The negative value of better parent heterosis for days to $50 \%$ flowering ranges from $-1.52 \%$ for the hybrid TX640 $\times$ L17 to $-4.69 \%$ for the hybrid TX640 $\times$ L21. Fourteen (14) hybrids recorded positive and significant better parent heterosis for grain yield. Twenty-four (24) hybrids had desirable negative and significant better parent heterosis for resistance to midge. On the other hand, 5 hybrids showed desirable negative significant better parent heterosis for days to $50 \%$ flowering (Table 3)

\section{Discussion}

In this experiment, significant differences are present among genotypes. The magnitude of the mean squares observed in this study for traits among the genotypes indicates that selection of genotypes with different levels of grain yield potential, resistance to midge, and flowering time will be possible. Sorghum cultivars that combine grain yield potential and resistance to sorghum midge are important for insect management in sorghum [17]. In the present study, hybrids TX640 × L6, TX640×L7, TX640×L13, and TX640 $\times$ L24 had high and significant heterosis for both grain yield and resistance to midge. Hamidou et al. [7] reported significant specific combining ability in the hybrid TX640 $\times$ L24 for grain yield, yield-related traits, and resistance to midge. In addition to expressing significant heterosis, these genotypes had high grain yield and less yield reduction caused by midge. These results indicate that breeding for sorghum hybrids that combine both grain yield
TABLE 2: Mean performance of 50 experimental hybrids evaluated in the 2015 rainy season.

\begin{tabular}{|c|c|c|c|}
\hline Crosses & $\begin{array}{c}\text { Grain yield } \\
(\mathrm{t} / \mathrm{ha})\end{array}$ & $\begin{array}{l}\text { Midge } \\
\text { damage }\end{array}$ & $\begin{array}{c}\text { Days to } 50 \% \\
\text { flowering }\end{array}$ \\
\hline TX640 × L1 & 6.18 & 0.72 & 65 \\
\hline QL33×1 & 3.84 & 0.35 & 65 \\
\hline $\mathrm{TX} 640 \times \mathrm{L} 2$ & 5.56 & 0.34 & 68 \\
\hline QL33× L2 & 3.99 & 0.79 & 64 \\
\hline TX640 $\times$ L3 & 4.34 & 0.45 & 66 \\
\hline QL33× L3 & 5.42 & 0.46 & 63 \\
\hline $\mathrm{TX} 640 \times \mathrm{L} 4$ & 8.37 & 0.59 & 67 \\
\hline QL33 × L4 & 10.39 & 0.15 & 67 \\
\hline TX640 × L5 & 4.03 & 0.61 & 66 \\
\hline QL33× L5 & 5.09 & 0.65 & 64 \\
\hline TX640 $\times$ L6 & 9.71 & 0.2 & 66 \\
\hline QL33×L6 & 4.63 & 0.77 & 66 \\
\hline TX640 $\times$ L7 & 10.65 & 0.25 & 67 \\
\hline QL33×L7 & 3.35 & 0.84 & 65 \\
\hline TX640 $\times$ L8 & 4.95 & 0.66 & 67 \\
\hline QL33×L8 & 5.83 & 0.57 & 64 \\
\hline TX640 × L9 & 3.65 & 0.54 & 67 \\
\hline QL33×L9 & 3.77 & 0.6 & 66 \\
\hline TX640 × L10 & 4.71 & 0.58 & 62 \\
\hline QL33 × L10 & 2.52 & 0.59 & 64 \\
\hline TX640 × L11 & 8.41 & 0.47 & 69 \\
\hline QL33× L11 & 1.17 & 0.3 & 64 \\
\hline TX640 × L12 & 4.56 & 0.6 & 69 \\
\hline QL33 × L12 & 4.87 & 0.61 & 64 \\
\hline TX640 × L13 & 9.89 & 0.25 & 64 \\
\hline QL33×L13 & 6.49 & 0.33 & 68 \\
\hline TX640 × L14 & 8.69 & 0.46 & 65 \\
\hline QL33 × L14 & 3.60 & 0.64 & 63 \\
\hline TX640 × L15 & 7.13 & 0.61 & 65 \\
\hline QL33 × L15 & 6.03 & 0.6 & 63 \\
\hline TX640 × L16 & 7.24 & 0.62 & 66 \\
\hline QL33 × L16 & 2.78 & 0.59 & 63 \\
\hline TX640 × L17 & 5.05 & 0.43 & 65 \\
\hline QL33× L17 & 2.71 & 0.81 & 66 \\
\hline TX640 × L18 & 12.78 & 0.74 & 66 \\
\hline QL33× L18 & 9.16 & 0.25 & 66 \\
\hline TX640 × L19 & 4.69 & 0.84 & 68 \\
\hline QL33 × L19 & 6.70 & 0.49 & 62 \\
\hline TX640 × LL20 & 8.21 & 0.54 & 67 \\
\hline QL33× L20 & 6.42 & 0.73 & 68 \\
\hline $\mathrm{TX} 640 \times \mathrm{L} 21$ & 8.32 & 0.59 & 61 \\
\hline QL33×L21 & 2.92 & 0.7 & 65 \\
\hline TX640 × L22 & 4.16 & 0.53 & 66 \\
\hline QL33× L22 & 3.29 & 0.64 & 63 \\
\hline $\mathrm{TX} 640 \times \mathrm{L} 23$ & 6.39 & 0.5 & 67 \\
\hline QL33 × L23 & 4.08 & 0.61 & 64 \\
\hline TX640 × L24 & 11.77 & 0.3 & 62 \\
\hline QL33 × L24 & 5.25 & 0.61 & 61 \\
\hline TX640 × L25 & 11.49 & 0.51 & 64 \\
\hline QL33 × L25 & 5.35 & 0.59 & 68 \\
\hline Grand mean & 5.91 & 0.54 & 65 \\
\hline LSD & & 0.44 & 4.19 \\
\hline
\end{tabular}

potential and resistance to sorghum midge can be achieved. Ashok Kumar [18] identified hybrids with grain yield potential and resistance to shoot fly in sorghum. Yerka et al. [19] reported the benefits of bmr-12 sorghum hybrids in both animal feeding and biofuel industries and 
TABLE 3: Better parent heterosis of 50 experimental hybrids evaluated in the 2015 rainy season.

\begin{tabular}{|c|c|c|c|}
\hline Crosses & $\begin{array}{l}\text { Grain } \\
\text { yield }\end{array}$ & $\begin{array}{c}\text { Midge } \\
\text { damage }\end{array}$ & $\begin{array}{c}\text { Days to } 50 \% \\
\text { flowering }\end{array}$ \\
\hline TX640 × L1 & $-15.24^{* *}$ & $33.33^{* *}$ & $0.00^{\mathrm{ns}}$ \\
\hline QL33×L1 & $-23.38^{* *}$ & $-39.66^{* *}$ & $0.00^{\mathrm{ns}}$ \\
\hline TX640 × L2 & $-23.77^{* *}$ & $-44.26^{* *}$ & $3.03^{*}$ \\
\hline QL33×L2 & $-18.75^{* *}$ & $29.51^{* *}$ & $-1.54^{\mathrm{ns}}$ \\
\hline TX640 × L3 & $-40.45^{* *}$ & $-11.76^{* *}$ & $3.13^{*}$ \\
\hline QL33 × L3 & $8.66^{* *}$ & $-20.69^{* *}$ & $-1.56^{\mathrm{ns}}$ \\
\hline TX640 × L4 & $-10.78^{* *}$ & $15.69^{* *}$ & $1.52^{\mathrm{ns}}$ \\
\hline QL33× L4 & $10.78^{* *}$ & $-74.14^{* *}$ & $3.08^{*}$ \\
\hline TX640 × L5 & $-44.76^{* *}$ & $-3.17^{* *}$ & $1.54^{\mathrm{ns}}$ \\
\hline QL33× L5 & $3.62^{* *}$ & $3.17^{* *}$ & $-1.54^{\mathrm{ns}}$ \\
\hline TX640 × L6 & $33.14^{* *}$ & $-60.78^{* *}$ & $0.00^{\mathrm{ns}}$ \\
\hline QL33× L6 & $-35.43^{* *}$ & $32.76^{* *}$ & $1.54^{\mathrm{ns}}$ \\
\hline TX640 × L7 & $46.05^{* *}$ & $-54.55^{* *}$ & $1.52^{\mathrm{ns}}$ \\
\hline QL33× L7 & $-52.17^{* *}$ & $44.83^{* *}$ & $0.00^{\mathrm{ns}}$ \\
\hline TX640 × L8 & $-32.10^{* *}$ & $6.45^{* *}$ & $1.52^{\mathrm{ns}}$ \\
\hline QL33×L8 & $8.16^{* *}$ & $-8.06^{* *}$ & $-1.54^{\mathrm{ns}}$ \\
\hline TX640× L9 & $-49.89^{* *}$ & $-3.57^{* *}$ & $1.52^{\mathrm{ns}}$ \\
\hline QL33× L9 & $-23.17^{* *}$ & $3.45^{* *}$ & $1.54^{\mathrm{ns}}$ \\
\hline TX640 × L10 & $-35.44^{* *}$ & $0.00^{\mathrm{ns}}$ & $-1.59^{\mathrm{ns}}$ \\
\hline QL33× L10 & $-48.62^{* *}$ & $1.72^{* *}$ & $1.59^{\mathrm{ns}}$ \\
\hline TX640 × L11 & $15.23^{* *}$ & $-7.84^{* *}$ & $4.55^{\mathrm{ns}}$ \\
\hline QL33×L11 & $-76.13^{* *}$ & $-48.28^{* *}$ & $-1.54^{\mathrm{ns}}$ \\
\hline TX640 × L12 & $-37.55^{* *}$ & $-1.64^{* *}$ & $4.55^{\mathrm{ns}}$ \\
\hline QL33× L12 & $-0.85 \mathrm{~ns}$ & $0.00 \mathrm{~ns}$ & $-1.54^{\mathrm{ns}}$ \\
\hline TX640× L13 & $20.76^{* *}$ & $-50.98^{* *}$ & $-3.03^{*}$ \\
\hline QL33× ×13 & $-20.76^{* *}$ & $-43.10^{* *}$ & $4.62^{* *}$ \\
\hline TX640 × L14 & $19.16^{* *}$ & $-16.36^{* *}$ & $1.56^{\mathrm{ns}}$ \\
\hline QL33×L14 & $-41.42^{* *}$ & $10.34^{* *}$ & $-1.56^{\mathrm{ns}}$ \\
\hline TX640× L15 & $-2.23^{* *}$ & $0.00 \mathrm{~ns}$ & $0.00^{\mathrm{ns}}$ \\
\hline QL33× L15 & $-8.38^{* *}$ & $-1.64^{* *}$ & $-3.08^{*}$ \\
\hline TX640 × L16 & $-0.69 \mathrm{~ns}$ & $3.33^{* *}$ & $3.13^{\mathrm{ns}}$ \\
\hline QL33× L16 & $-43.39^{* *}$ & $-1.67^{* *}$ & $-1.56^{\mathrm{ns}}$ \\
\hline TX640 × L17 & $-30.79^{* *}$ & $-30.65^{* *}$ & $-1.52^{\mathrm{ns}}$ \\
\hline QL33× L17 & $-44.77^{* *}$ & $30.65^{* *}$ & $1.54^{\mathrm{ns}}$ \\
\hline TX640 × L18 & $16.53^{* *}$ & $45.10^{* *}$ & $0.00^{\mathrm{ns}}$ \\
\hline QL33× L18 & $-16.53^{* *}$ & $-56.90^{* *}$ & $1.54^{\mathrm{ns}}$ \\
\hline TX640 × L19 & $-35.68^{* *}$ & $44.83^{* *}$ & $4.62^{* *}$ \\
\hline QL33× L19 & $8.11^{* *}$ & $-15.52^{* *}$ & $-4.62^{* *}$ \\
\hline TX640 × LL20 & $9.60^{* *}$ & $-12.90^{* *}$ & $1.52^{\mathrm{ns}}$ \\
\hline QL33× L20 & $-14.39^{* *}$ & $17.74^{* *}$ & $4.62^{* *}$ \\
\hline TX640 × L21 & $14.02^{* *}$ & $-7.81^{* *}$ & $-4.69^{\mathrm{ns}}$ \\
\hline QL33×L21 & $-47.98^{* *}$ & $9.37^{* *}$ & $1.56^{\mathrm{ns}}$ \\
\hline TX640 × L22 & $-43.02^{* *}$ & $-8.62^{* *}$ & $1.54^{\mathrm{ns}}$ \\
\hline QL33× L22 & $-32.93^{* *}$ & $10.34^{* *}$ & $-3.08^{*}$ \\
\hline TX640 × L23 & $-12.46^{* *}$ & $-9.09^{* *}$ & $1.52^{\mathrm{ns}}$ \\
\hline QL33× L23 & $-21.99^{* *}$ & $5.17^{* *}$ & $-1.54^{\mathrm{ns}}$ \\
\hline TX640 × L24 & $61.40^{* *}$ & $-43.40^{* *}$ & $0.00^{\mathrm{ns}}$ \\
\hline QL33 × L24 & $-23.67^{* *}$ & $5.17^{* *}$ & $-1.61^{\mathrm{ns}}$ \\
\hline TX640 × L25 & $36.48^{* *}$ & $-7.27^{* *}$ & $-3.03^{*}$ \\
\hline QL33 × L25 & $-36.48^{* *}$ & $1.72^{* *}$ & $4.62^{* *}$ \\
\hline
\end{tabular}

Note: ${ }^{* *}$ significant at $1 \%,{ }^{*}$ significant at $5 \%$, and ns: nonsignificant.

recommended its use in large-scale production. Ashok Kumar (2011) documented hybrids with both high grain yield and grain mold resistance in sorghum and suggested these hybrids as a potential source for grain mold resistance breeding.
The parental lines involved in the hybrids described here can be advanced and exploited in commercial sorghum hybrids with superior grain yield and resistance to sorghum midge. The heterosis for grain yield and resistance to sorghum midge identified in this study can also provide a source of midge resistance and grain yield increase in developing new sorghum cultivars for midge resistance and grain yield increase. On the other hand, the hybrids QL33 $\times$ L1, TX640 $\times$ L2, QL33 $\times$ L3, QL33 $\times$ L4, QL33 $\times$ L11, QL33 $\times$ L13, TX640 $\times$ L17, and QL33 $\times$ L18 recorded higher better parent heterosis for resistance to midge and low yield loss caused by midge. The parents of these hybrids can be used to develop midge-resistant hybrids. Patil et al. [20] documented high heterosis for midge resistance traits in twenty-eight sorghum hybrids. Specific combining ability effects for resistance to sorghum midge was reported in hybrids TX640 $\times$ L17 and TX640 $\times$ L2 by Hamidou et al. [7]. The hybrid TX640 $\times$ L25 with high significant heterosis for grain yield can be an important candidate for grain yield $[21,22]$.

\section{Conclusion}

From the results, high levels of better parent heterosis were evident for grain yield and resistance to sorghum midge among the hybrid evaluated here. The top promising crosses were TX640 $\times$ L6, TX640 $\times$ L7, TX640 $\times$ L13, and TX640 $\times$ L24 for both grain yield and resistance to midge and QL33 $\times \mathrm{L} 1, \quad$ TX640 $\times$ L2, QL33 $\times$ L3, QL33 $\times$ L4, QL33 $\times$ L11, QL33 $\times$ L13, TX640 $\times$ L17, and QL33 $\times$ L18 for resistance to midge. These crosses need to be evaluated in a wide range of environments to identify the most stable for further exploitation $[23,24]$.

\section{Data Availability}

The underlying data supporting the results can be found at hmassaoud@yahoo.fr.

\section{Conflicts of Interest}

The authors declare that they have no conflicts of interest.

\section{References}

[1] Faostat, Statistical Yearbook, World Food and Agriculture. FAO Food Agric. Organziation UN, Rome Italy, 2014, http:// faostat.fao.org/site/291/default.aspx.

[2] N. Maman, S. C. Mason, D. J. Lyon, and P. Dhungana, "Yield components of pearl millet and grain sorghum across environments in the Central Great Plains," Crop Science, vol. 44, no. 6, pp. 2138-2145, 2004.

[3] H. C. Sharma, B. L. Agrawal, P. Vidyasagar, C. V. Abraham, and K. F. Nwanze, "Identification and utilization of resistance to sorghum midge, Contarinia sorghicola (Coquillet), in India," Crop Protection, vol. 12, no. 5, pp. 343-350, 1993.

[4] H. C. Sharma and G. L. Teetes, "Yield loss assessment and economic injury levels for panicle-feeding insects of sorghum," in Panicle Insect Pests of Sorghum and Pearl Millet: Proceedings of an International Consultative Workshop, 4-7 Oct 1993, K. F. Nwanze and O. Youm, Eds., p. 320, 
International Crops Research Institute for the Semi-Arid Tropics, Sahelian Niamey, Niger, 1995.

[5] M. B. Amadou, Comportement Agronomique et Résistance á la Cécidomye des Descendances Non Sélectionnées de Sorgho, Diplome dingénieur agronome, IPR/IFRA de Katibougou, Bamako, Mali, 1999.

[6] H. A. Kadi Kadi, I. Kapran, and B. B. Pendleton, "Identification of sorghum genotypes resistant to sorghum midge in Niger," International Sorghum and Millets Newsletter, vol. 46, pp. 57-59, 2005.

[7] M. Hamidou, M. Ba, I. Kapran, E. Y. Danquah, K. Ofori, and V. Gracen, "Combining ability for grain yield and resistance to midge Stenodiplosis sorghicola (Coquillett) in sorghum (Sorghum bicolor (L.) Moench)," Journal of Plant Breeding and Genetics, vol. 4, no. 2, pp. 19-33, 2017.

[8] B. V. Reddy, H. C. Sharma, R. P. Thakur, S. Ramesh, F. Rattunde, and M. Mgonja, "Sorghum hybrid parents research at ICRISAT-strategies, status and impacts," Journal of SAT Agricultural Research, vol. 2, no. 1, pp. 1-24, 2006.

[9] B. A. Franzmann, A. T. Hardy, D. A. H. Murray, and R. G. Henzell, "Host-plant resistance and biopesticides: ingredients for successful integrated pest management (IPM) in Australian sorghum production," Australian Journal of Experimental Agriculture, vol. 48, no. 12, pp. 1594-1600, 2008.

[10] D. M. Bahadure, S. Marker, A. V. Umakanth, Prab hakar, J. V. Patil, and G. J. Synerem, "Exploitation of the Heterosis for bioethanol production in sweet sorghum 5Sorghum bicolor L. Moench) hybrids," The Bioscane, vol. 9, no. 4, pp. 1641-1646, 2014.

[11] F. Hochholdinger and N. Hoecker, "Towards the molecular basis of heterosis," Trends in Plant Science, vol. 12, no. 9, pp. 427-432, 2007.

[12] K. R. Lamkey and J. W. Edwards, "The quantitative genetics of heterosis. p. 31-48," in Proceedings of the International Symposium on the Genetics and Exploitation of Heterosis in Crops, J. G. Coors and S. Pandey, Eds., CIMMYT, Mexico City, Mexico, August 1997.

[13] J. C. Reif, F.-M. Gumpert, S. Fischer, and A. E. Melchinger, "Impact of interpopulation divergence on additive and dominance variance in hybrid populations: figure 1," Genetics, vol. 176, no. 3, pp. 1931-1934, 2007.

[14] O. Kempthorne, An Introduction to Genetic Statistics, Jhon wiley sons, NY, USA, 1957.

[15] J. H. Turner, "A study of heterosis in upland cotton II. Combining ability and inbreeding effects 1," Agronomy Journal, vol. 45, no. 10, pp. 487-490, 1953.

[16] H. K. Hayes, F. R. Immer, and D. C. Smith, Methods of Plant Breeding, Mc. Grow Hill Book. Co. Inc., New York, NY, USA, 1955.

[17] A. Ashok Kumar, B. V. Reddy, B. Ramaiah, and R. Sharma, "Heterosis in white-grained grain mold resistant sorghum hybrids," Crop Protection, vol. 37, pp. 7-12, 2011.

[18] A. Ashok Kumar, B. V. S. Reddy, H. C. Sharma, and B. Ramaiah, "Shoot fly (Atherigona soccata) resistance in improved grain sorghum hybrids," Journal of SAT Agricultural Research, vol. 6, 2008.

[19] M. K. Yerka, A. Watson, J. J. Toy, G. Erickson, J. F. Pedersen, and R. Mitchell, "Yield and forage value of a dual-purposebmr-12Sorghum hybrid," Crop Science, vol. 55, no. 2, pp. 681-687, 2015.

[20] D. G. Patil, R. H. Patel, and G. G. Adsul, "Heterosis for resistance to midge in sorghum [Sorghum bicolor (L.) Moench]," Advances in Plant Sciences, vol. 23, no. 1, pp. 267-269, 2010.
[21] S. Hemalatha, G. S. Sharma, and D. Amit, "Heterosis for grain yield and its component traits in sorghum (Sorghum bicolor L. Moench)," Annuals of Agricultural Research, vol. 24, pp. 579-582, 2003.

[22] S. L. Kaul, S. M. Rafiq, and K. Singh, "Heterosis and combing ability for grain yield and yield components in post rainy season sorghum," International Sorghum and Millets Newsletter, vol. 44, pp. 21-23, 2003.

[23] H. K. Hayes, F. R. Immer, and D. C. Smith, Methods of Plant Breeding, Mc. Grow Hill Book. Co. Inc., NY, USA, 1955.

[24] H. Sharma, G. S. Sharma, and D. Amit, "Heterosis for grain yield and its component traits in sorghum," Annals of Agricultural Sciences, vol. 24, no. 3, pp. 579-582, 2003. 